\title{
Conversion of Plastic to Hydrocarbon
}

\author{
${ }^{1}$ Siddhant Pundhir, and ${ }^{2}$ Arpit Gagneja
}

\begin{abstract}
Plastics are an integral part of our modern life and are used in almost all daily activities. Since plastics are synthesized from non-renewable sources and are generally not biodegradable, waste plastics are the cause of many of the serious environmental problems the world faces today. However, waste plastics can become a source of enormous energy with the correct treatment. According to a recent study performed by the Environmental Protection Agency (EPA) approximately 48 million tons of waste plastic are generated in the USA alone, to be specific PETE-1 (10\%), HDPE-2 (19\%), PVC-3 (6\%), LDPE-4 (23\%), PP-5 (14\%), PS-6 (9\%) and Other-7 (19\%). Statistics show that approximately $10 \%$ of this plastic is recycled, $25 \%$ is incinerated and the remaining $65 \%$ is dumped in landfills. Established technology can convert waste plastics into a renewable source of hydrocarbon fuel. This technology plans to acquire waste plastics from City / Local Municipalities and Recycling Facilities. For plastic fuel production purposes the plastics can be collected or separated into different categories.

Thermal conversion process was applied with three types of waste plastic mixture and waste plastics mixture to liquid hydrocarbon fuel production in present of oxygen under laboratory Labconco fume hood without adding any kind of catalyst. Utilization of the process described can reduce the impact of waste plastics significantly. Thermal decomposition of the most common plastics such as high density polyethylene (HDPE), polypropylene (PP) and polystyrenes (PS) has been conducted to produces a mixture of hydrocarbons.

Thus a major waste could be utilised to create hydrocarbon, which has somehow become a necessity in today's fast moving world.
\end{abstract}

Keywords - Polypropylene, Fuel, light fraction, hydrocarbon, waste plastic, GC/MS.

\section{INTRODUCTION}

In recent years, population explosion and changes in people's consumption patterns have resulted in generation of large amounts of waste plastic as municipal solid waste. In 2010, Americans generated about 250 million tons of trash and recycled and composted over 85 million tons of this material, equivalent to a 34.1 percent recycling rate. On average, we recycled and composted 1.51 pounds out of our individual waste generation of 4.43 pounds per person per day. In India, information given by the Central Pollution Control Board (CPCB) in 2013 suggested that the total plastic waste collected and recycled in the country was estimated to be 15,341 tons per day and 6,137 tons remain uncollected and littered.

At these alarming levels of waste plastics generation, India needs to prepare a lot in recycling and disposing the waste and find an efficient treatment strategy. In our country, 70\% of the MSW is now disposed of as landfill as land filling wastes the

\footnotetext{
${ }^{1,2}$ Chemical engineering Department, Pandit Deendayal Petroleum University, Gandhinagar, Gujarat, India
}

resources and pollutes the land with macromolecules of nonbiodegradable plastic.

However, over the last few decades, the generation, recycling, composting, and disposal of MSW have changed substantially. Recycling is the best possible solution to the environmental challenges facing the plastic industry and thermal recycling of waste polymers under different catalytic and thermal circumstances has been well investigated and is the most common method of conversion.

However, as an alternative strategy to chemical recycling, conversion of waste plastics into basic petrochemicals (to be used as hydrocarbon feedstock or fuel oil for a variety of downstream processes) has attracted much interest recently. There are different methods of obtaining fuel from waste plastic such as thermal degradation, catalytic cracking, and gasification

The most common plastics preferred for the feedstock of the production of liquid hydrocarbon are high density polyethylene (HDPE), polypropylene (PP) and polystyrenes (PS) which yield a mixture of hydrocarbons. High-density polyethylene (HDPE), a polyethylene thermoplastic made from petroleum, is used for production of light hydrocarbons catalytically, and polystyrene (PS), a synthetic aromatic polymer of styrene is a liquid petrochemical is converted to hydrocarbon by microwave-metal interaction pyrolysis. Polypropylene (PP) is a hydrocarbon polymer made from petrochemicals; having a large amount of volatile matter ( $>99$ wt \%) with high heating value and low ash content $(<0.1 \mathrm{wt}$ $\%)$; which may favor a better product yield from thermal decomposition.

Thermal decomposition of plastic polymers is becoming an increasingly important method for the conversion of plastic materials into valuable chemicals and oil products. Thermal and catalytic cracking process of waste polymers are also economically and environmentally accepted methods for utilization.

In this work, polypropylene (PP) is chosen as the representative of plastic waste. The products of such processes are liquid hydrocarbon mixtures in the temperature range of $35-360{ }^{\circ} \mathrm{C}$, gaseous hydrocarbons and solid residue. Different type of catalysts, acid silica-alumina or zeolite (HY, HZSM-5) containing ones and alkaline compounds such as $\mathrm{ZnO}, \mathrm{CaO}$ and $\mathrm{K} 2 \mathrm{O}$ can also be applied, but they deactivate very quickly. Through the years varied and terrific results have been obtained from liquefaction of individual polymers (Polyethylene (PE), Polypropylene (PP), Polystyrene (PS) etc.) and relatively clean mixed plastics using solid acid catalysts and metal-promoted solid acid catalysts. Companies worldwide are making inroads in the waste plastic-to-fuel arena. One such company in Australia is Ozmotech which 
converts waste plastic into diesel fuel through a process that includes liquefaction, pyrolysis, catalytic breakdown of high Molecular weight vapours and controlled distillation. People at various places in the world have been experimenting this conversion for a better result. For example, Venkatesh et al. (1996) and Shabtai et al. (1997) have obtained high yields of liquids that consist predominantly of isoalkanes in the gasoline boiling range from HDPE, PP, and PS at relatively low temperature $\left(300-375{ }^{\circ} \mathrm{C}\right)$ using catalysts such as silicaalumina or zeolite (HY, HZSM-5, mordenite) containing alkaline compounds such as $\mathrm{ZnO}, \mathrm{CaO}$ and $\mathrm{K} 2 \mathrm{O}$.

Batch experiments are usually carried out at laboratory scale (1-500 g) using one or two types of polymers, which are clean and not waste polymers. There have been large amount of experiments been conducted with PE, PP and PS in a continuous flow stirred tank reactor in many different studies. It was found that the degradation by continuous flow operation is a suitable technique for converting waste polymers into liquid hydrocarbon. The volatile products could be used as feedstock components, e.g. in refineries. Their further utilization for petrochemical purposes has not yet been solved.

Many researches involving thermal degradation of waste plastics into liquid fuel have been conducted. Thermal degradations are not only used for polymer but it is also used for aromatics and gas. Furthermore, some researchers have been also conducted using catalytic degradation and pyrolysis resulting in successful outcomes.

\section{MATERIALS AND METHOD}

\section{A. Materials and Preperation}

The raw materials used for the experiment were HDPE, PP and PS. Raw samples were collected form municipality. The collected waste plastics were dirty and come with foreign materials. HDPE waste plastic sample was white colour milk container, PP waste plastic samples was white colour food container and PS waste plastic samples was transparent food containers. All foreign materials were separated by manually And then waste plastic collected were cleaned and washed with liquid soap. Washed waste plastics were cut manually into small pieces by scissor and grinded into 3-4 mm size. The raw materials elemental composition is presented in table 1 . PP waste hard plastic and grounded PP waste plastic sizes were of $3.4 \mathrm{~mm}$ then transferred into reactor chamber for liquefaction process.

TABLE I: WASTE PLASTICS ELEMENTAL COMPOSITION (WT. \%) BY EA-2400

\begin{tabular}{|l|l|l|l|}
\hline \multirow{2}{*}{$\begin{array}{c}\text { Sample } \\
\text { Name }\end{array}$} & \multicolumn{3}{|c|}{ Composition of elements } \\
\cline { 2 - 4 } HDPE & 83.57 & 14.78 & $<0.3$ \\
\hline PP & 79.93 & 14.17 & $<0.3$ \\
\hline PS & 78.60 & 7.21 & $<0.3$ \\
\hline
\end{tabular}

\section{B. Material Pre-Analysis}

PP hard waste plastic was pre-analysis by using GC/MS Clarus 500 series with CDS pyroprobe 5000 series. Pyroprobe used for hard sample volatile and sent to GC column through mass detection and chromatogram displayed compound structure with different retention time. Pyroprobe temperature used $1200{ }^{\circ} \mathrm{C}$ for volatile sample for GC. Elemental analyser 2400 series used for carbon, hydrogen and nitrogen percentage determination by used ASTM method (5291.a) and results was shown from transparent polypropylene carbon was 79.93\%, hydrogen $14.17 \%$ and nitrogen was $<0.30 \%$. FT-IR Spectrum 100 series was use raw material functional group and wave band number energy determination and at the end TGA pyrias-1 was use for raw material onset temperature and how much percentage sample was volatile by using temperature and in convenient time.

\section{EXPERIMENTAL PROCESS}

In the first step, thermal degradation of PP waste plastics is been conducted in laboratory in a small scale measure under Labconco fume hood without catalyst and vacuum system. For small-scale laboratory process the weight of input waste plastics weight $600 \mathrm{gm}$ (see fig 1). The process of conversion of the individual waste particle into alternative hydrocarbon fuel energy begins with heating the solid plastic without the presence of cracking catalyst. It takes place under atmosphere to form liquid slurry and temperature range used for thermal degradation varies between120-140C. The produced fuel density is $0.74 \mathrm{gm} / \mathrm{ml}$. In excess to be obtained the liquid hydrocarbon fuel they also received light gaseous hydrocarbon compounds (C1-C4) which resembled the natural gas. Individual PP waste plastic experiment took time 5-6 hours and also input electricity for every individual experiment 13$15 \mathrm{kWh}$ for 1 gallon production. Produced fuel is purified by RCI fuel purification system to remove all water and other sediments. Light gas was transferred to gas cleaning device to remove gas emission.

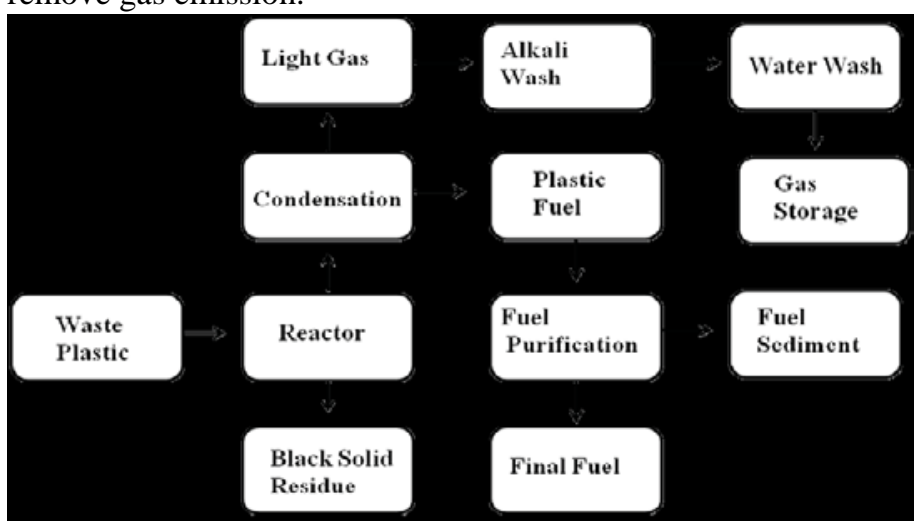

Fig. 1: 1st step process for fuels production of PP waste plastics

For fractional distillation process (2nd step process), PP plastic fuel is put into a reactor to obtain further distillate. There are five different temperature profile in a fractional column. For 1st fraction fuel temperature setup to be collected at $40-60{ }^{\circ} \mathrm{C}$, 2ndfraction fuel temperature setup at $110-120^{\circ} \mathrm{C}$, 3rdfraction fuel temperature setup at $180-200{ }^{\circ} \mathrm{C}$, 4 th fraction fuel temperature setup at $260-280{ }^{\circ} \mathrm{C}$ and 5 th fraction fuel temperature setup at $320-360{ }^{\circ} \mathrm{C}$. 1 st fractional fuel density is $0.72 \mathrm{gm} / \mathrm{ml}$, 2nd fractional fuel density is $0.78 \mathrm{gm} / \mathrm{ml}$, 
3rdfractional fuel density is $0.80 \mathrm{gm} / \mathrm{ml}$, 4th fractional fuel density is $0.82 \mathrm{gm} / \mathrm{ml}$ and 5 th fractional fuel density is 0.84 $\mathrm{gm} / \mathrm{ml}$. During 2nd fractional distillation period a type of light gas is also produced and is clean with alkali wash and after wash the cleaned light gas is stored in a gas cylinder for future use and analysis. By using this process $12 \%$ light fraction liquid hydrocarbon fuel was collected and light gas was $3 \%$ and rest of $85 \%$ different grade fuel collected with different temperature range.

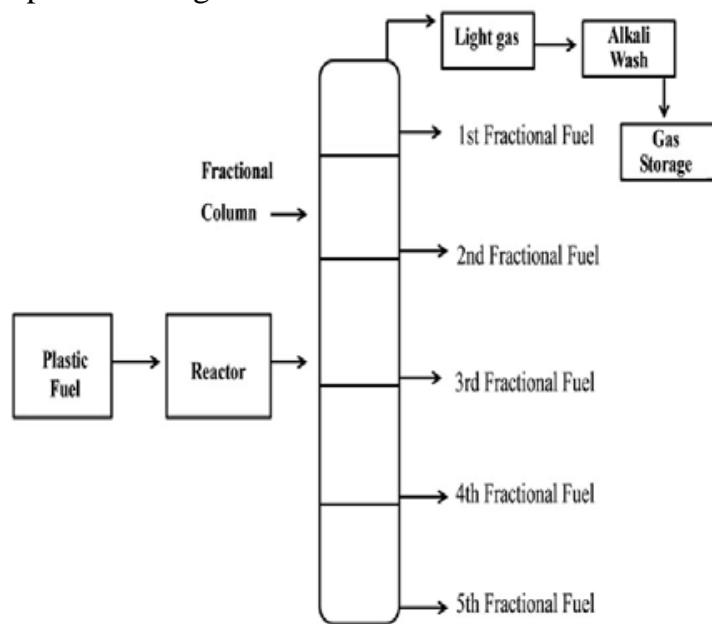

Fig. 2: 2nd step process PP waste plastic fuel to 1st fractional fuel production

\section{RESUlt AND DisCUSSION}

\section{A. Analysis Technique}

Perkin Elmer Differential Scanning Calorimeter (DSC) was used for indication of liquid fuel boiling point and fuel enthalpy value. The temperature range was $0-400{ }^{\circ} \mathrm{C}$ and temperature increased rate was $10{ }^{\circ} \mathrm{C} / \mathrm{min}$. Carrier gas was used nitrogen at $20 \mathrm{ml} / \mathrm{min}$. Perkin Elmer Elite-5MS Capillary Column Length is 30 meter, $0.25 \mathrm{~mm}$ ID, 0.5 um df, Maximum Program Temperature $350^{\circ} \mathrm{C}$, Minimum Bleed at $330^{\circ} \mathrm{C}$.

The experimental set up for sample analysis is as follows: Initial temperature $40{ }^{\circ} \mathrm{C}$, in temperature $325^{\circ} \mathrm{C}$, temperature ramping $10{ }^{\circ} \mathrm{C}$ per minute, final temperature hold for 15 minutes. Total sample run time is 44.50 minute. Sample inject volume is $0.5 \mathrm{~L}$, helium used as a career gas, Split Flow $=101.0$ $\mathrm{ml} /$ minute and mass program set up type MS scan, Ion Mode EI+, Data format - Centroid, Start Mass 35.00, End Mass 528.00,Scan Time (Sec)0.25, Start Time (min) 1.00, End Time (min) 44.50. For Perkin Elmer GCMS analysis purposes, a National Institute of standard testing (NIST-2002) mass spectral libraries software is used as library compound and in the analysis only those compounds are detected by their trace mass and retention time. Perkin Elmer FT-IR (Spectrum 100) used for raw sample per analysis and liquid sample analysis. Raw waste plastic sample was analyzed by diamond crystal plate KRS 5 and their functional group and band energy value was checked. Liquid fuel sample was analyzed by $\mathrm{NaCl}$ cell of $0.025 \mathrm{~mm}$ thickness. Both samples analysis by same parameter was used such as scan number was 32, resolution 4 and range $4000-450 \mathrm{~cm}$.
The analyzer was used for raw waste plastics carbon; hydrogen and nitrogen percentages determine and follow ASTM method ASTM D5291.a. Carrier gas used was helium, oxygen and nitrogen. Perkin Elmer Thermogavimetric (TGA Pyris-1) was used for raw waste plastics onset temperature measuring. Temperature range was 50 to $800{ }^{\circ} \mathrm{C}$ and temperature ramping range used for onset temperature 10 ${ }^{\circ} \mathrm{C} / \mathrm{min}$. Helium gas was used as a carrier at $20 \mathrm{psi}$.

\section{B. Residue Analysis}

Solid black residue metal contained analysis was performed by ICP -AES ASTM D1976. Table II shows residue carbon, hydrogen and nitrogen percentage. PP waste plastics to black solid residue were analyzed by ICP (Induced Couple Plasma) and numerous metal contents are found in the analysis stated that some metal content are very high compare to less contents metal in the residue.

In waste PP residue analysis, less organic and inorganic element content are constituents of residue. Despite all of these factors involved, most of the portion of carbon and hydrogen contents is converted to liquid fuel because of condensation and at certain temperature it remains at liquid state as fuel. Rest of carbon and hydrogen contents are remain as a residue at the terminate phase of the experiment with other additives and metal/ non-metal components.

TABLE II: PP Waste Plastic To Black Solid Residue ICP TRace Metal ANALYSIS RESULT

\begin{tabular}{|l|l|l|l|}
\hline \multicolumn{5}{|c|}{ Test Method: ASTM D1976 } \\
\hline \multicolumn{1}{|c|}{ Metal Name } & \multicolumn{1}{|c|}{ Results (ppm) } & \multicolumn{1}{c|}{ Metal Name } & Results (ppm) \\
\hline Aluminium & 1517 & Magnesium & 1480 \\
\hline Arsenic & 24.5 & Manganese & 8.8 \\
\hline Antimony & $<1.0$ & Nickel & 11.9 \\
\hline Boron & 3.3 & Potassium & 127.7 \\
\hline Barium & 11.8 & Sodium & 213.4 \\
\hline Beryllium & $<1.0$ & Silver & $<1.0$ \\
\hline Calcium & 134300 & Selenium & $<1.0$ \\
\hline Cadmium & $<1.0$ & Silicon & 8.4 \\
\hline Chromium & 4.0 & Tin & 273.7 \\
\hline Copper & 3.8 & Titanium & 558.4 \\
\hline Iron & 538.7 & Vanadium & $<1.0$ \\
\hline Lead & $<1.0$ & Zinc & 433.3 \\
\hline Lithium & 29.3 & & \\
\hline
\end{tabular}

High content metal elements are Aluminium 4,570 ppm (ppm=Perts per million), Boron 2,701 ppm, Calcium 16,740 ppm, Chromium 2,696 ppm, Copper 1,687 ppm, Iron 395,600 ppm, Magnesium 4,001 ppm, Manganese 1,375 ppm, Sodium $58,290 \mathrm{ppm}$, Tin 37,520 ppm, Titanium 2,674 ppm, Zinc $5,598 \mathrm{ppm}$. On the other hand less content metal elements are following Silver $<1.0 \mathrm{ppm}$, Arsenic $<1.0 \mathrm{ppm}$, Barium 14.2 ppm, Beryllium <1.0 ppm, Cadmium 9.1 ppm, Potassium $<1.0$ ppm, Lithium 8.7 ppm, Nickel 379.6 ppm, Lead 19.2 ppm, Antimony <1.0 ppm, Selenium 132.3 ppm, Silicon 28.2 ppm 
and eventually Vanadium $<1.0 \mathrm{ppm}$ as well. PP Waste plastics are fallen in the open nature for long run and contaminated with different metal / Non-metal and other materials of soil and air components as well as in the residue analysis, various elements' content appeared. Elemental Analyzer (EA 2400) analysis of PP Waste plastics to Black solid residue Carbon and Hydrogen and other contents are mentioned: Carbon 45.77\%, Hydrogen $1.14 \%$ and Nitrogen $1.30 \%$ etc.

\section{C.Produced Fuel Analysis}

Gas Chromatography and -Mass Spectrometer analysis of PP plastic fuel to1st fractional fuel (figure 3 and table 3) in accordance with the various retention time and trace masses different types of hydrocarbon compounds are appeared in the analysis result index. Many compounds are emerged on the analysis in the range -C3 to C10. Among them, few compounds are discussed based on the retention time and trace mass following hydrocarbon compounds at the initial phase of the analysis at retention time $1.50 \mathrm{~min}$ and trace mass 39 , compound is Cyclopropane (C3H6), retention time 1.56 and trace mass 43, compound is Isobutane ( $\mathrm{C} 4 \mathrm{H} 10$ ), retention time 1.59 and trace mass 39, compound is 1-Propene,2methyl- (C4H8), retention time 1.61 and trace mass 41,compound is 2-Butene,(E), ( C4H8), retention time 1.75 and trace mass 55, compound is 1-Butene, 3-methyl- ( C5H10), retention time 2.56 and trace mass 41 , compound is Hexane (C6H14), retention time 2.64 and trace mass 68,compound is 4-Heptenal, (Z)- (C7H12O), retention time 2.72 and trace mass 67, compound name is 2,4 -Hexadiene, (Z,Z)- (C6H10), retention time 2.94 and trace mass 67,compound name is trans-1,4-Hexadiene ( $\mathrm{C} 6 \mathrm{H} 10$ ), retention time 3.55 and trace mass 41 , compound is Cyclopentane,1,2-dimethyl-,cis-( C7H14), retention time 4.59 and trace mass 43, compound is -Heptene-4-methyl-( C8H16), retention time 5.54 and trace mass 83 , compound is Cyclopentane,1,1,3,4-tetramethyl-,cis-( C9H18), retention time 5.91 and trace mass 69, compound is Cyclohexane, 1,3,5trimethyl-, (1,3,5)- (C9H18), retention time 6.57 and trace mass 109 compound is Cyclohexene,3,3,5-trimethyl-( C9H16), retention time 7.24 and trace mass 55 , compound is 3 Octyne,2-methyl-( C9H16) , retention time 8.86 and trace mass 43, compound is Octane, 3,5-dimethyl-( C10H22), retention time 8.92 and trace mass 43 , compound is Octane, 3,5-dimethyl- (C10H22). Ultimately also at retention time 10.1 and trace mass 43 , compound is 3-Tridecene, (E)--( C13H26) and retention time 10.07 and trace mass 43 ,compound is Cyclooctane, 1,4-dimethyl-, cis- (C10H20) etc.

\section{V.CONCLUSION}

It is very much essential to scientifically dispose the ever increasing solid wastes generated by the growing population. PP waste plastic fuel to first fraction fuel collected during the production process consists of very light groups of hydrocarbons. Those carbon ranges from C3 - C10. The carbon range represents the viscosity of the fuel and gives us a view about how effective the fuel can be. This fuel is very bright in ppearance, it density is measured at $0.72 \mathrm{gm} / \mathrm{ml}$. The fuel derived from the PP waste plastics is considered to be a cleaned product since an analytical test of the fuel indicates it has low sulfur and other harmful contents. Since the PP fuel in low in density it is a very light able and flammable fuel. A practical burn test was conducted for the PP fuel to compare against similar commercial gasoline fuel. The PP fuel had a slightly higher burning time than the gasoline fuel because it contained a higher carbon chain of C3 - C10 compared to gasoline carbon chain of C3 - C9.

\section{ACKNOWLEDGMENT}

We would like to sincerely thank the Chemical Engineering Department of Pandit Deendayal Petroleum University to provide us with such an opportunity. We would like to express our gratitude to our professors for making us understand this topic.

\section{REFERENCES}

[1] Achilias DS, Roupakias C, Magalokonomosa P, Lappas AA, Antonakou EV. Chemical recycling of plastic wastes made from polyethylene (LDPE and HDPE) and polypropylene (PP), Journal of Hazardous Materials 2007; 149:536-542.

http://dx.doi.org/10.1016/j.jhazmat.2007.06.076

[2] Angyal A, Miskolczi N, Bartha L (2007). Petrochemical feedstock by thermal cracking of plastic waste. J. Anal. Appl. Pyrolysis. 79: 409-414. http://dx.doi.org/10.1016/j.jaap.2006.12.031

[3] Arena U, Zaccariello L, Mastellone ML (2010). Fluidized bed gasification of waste-derived fuels. Waste Management. 30: 1212-1219. http://dx.doi.org/10.1016/j.wasman.2010.01.038

[4] Ding W, Liang J, Anderson LL (1997). Thermal and catalytic degradation of high density polyethylene and commingled postconsumer plastic waste. Fuel http://dx.doi.org/10.1016/s0378-3820(96)01080-6

[5] Processing Technology. 51: 47-62.

[6] Balakrishnan RK, Guria C. Thermal degradation of polystyrene in the presence of hydrogen by catalysts in solution. Polymer Degradation and Stability 2007; 92:1583-1591. http://dx.doi.org/10.1016/j.polymdegradstab.2007.04.014

[7] Gimouhopoulos K., Doulia D, Vlyssides A, Georgiou D (1998). Organic solvent effects on waste plastics-lignite coliquefaction. Resources Conservation and http://dx.doi.org/10.1016/S0921-3449(98)00006-8

[8] Recycling. 23: 47-56.

[9] Helene A, Lecomte, John JL (2008). Commercial fire-retarded PET formulations e Relationship between thermal degradation behaviour and fire-retardant action.

[10] Polymer Degradation and Stability. 93: 498-506. http://dx.doi.org/10.1016/j.polymdegradstab.2007.11.005 